\title{
O ENSINO SUPERIOR SOB A ÓTICA DE ALUNOS CONTEMPLADOS PELO PROUNI
}

\author{
T. GOMES ${ }^{1}$, A. TAVARES ${ }^{2}$ e P. MORAIS ${ }^{3}$ \\ ${ }^{1,2}$ Políticas Públicas e Gestão Escolar - Instituto Federal do Rio Grande do Norte \\ E-mail: tarcimaria.gomes@ifrn.edu.br ${ }^{1}$ - andrezza.tavares@ifrn.edu.br ${ }^{2}$ - pauleany.morais@ifrn.edu.br ${ }^{3}$
}

Artigo submetido em maio/2012 e aceito em maio/2012

\section{RESUMO}

No Brasil contemporâneo, razões estruturais impedem que grande parcela da população consiga avançar no nível do ensino. O Programa Universidade para Todos, o ProUni, é um programa do Ministério da Educação - MEC, criado pelo Governo Federal no ano de 2004, e que tem como finalidade a concessão de bolsas de estudo integrais e parciais em instituições de educação superior privadas, em cursos de graduação e sequenciais de formação específica, a estudantes brasileiros e de baixa renda que não possuem diploma de nível superior. A pesquisa foi realizada em uma instituição de ensino superior da rede privada de ensino, localizada na zona sul de Natal-RN, com o objetivo de identificar as representações sociais de universidade entre os sujeitos investigados. Participaram da análise os textos e respostas de 80 alunos recém-admitidos ao Ensino Superior através do processo seletivo do ProUni.

PALAVRAS-CHAVE: políticas públicas, universidade, ProUni.

\section{THE UNIVERSITY AS SEEN BY THE PROUNI STUDENTS}

\section{ABSTRACT}

In comtemporary Brazil, structural reasons prevent that a big part of the population advance in the educational system. The program "Universidade para Todos", translated as "University for Everyone", also known as "ProUni", is a program developped by the Ministry of Education (MEC), created by the federal government in 2004, and it has the objective of conceding full and partial scholarships in private higher education institutions, to undergraduate and graduate studies, to brazilian students who come from families of lowincome and do not yet have a university degree. The research was conducted in a private university, located in the south of Natal-RN, with the objective of identify the social representation of universities between the observed subjects. Were part in this analysis the texts and answers of 80 recently-admitted students to the institution, selected through the ProUni process.

KEY-WORDS: public policies, university, ProUni. 


\section{O ENSINO SUPERIOR SOB A ÓTICA DE ALUNOS CONTEMPLADOS PELO PROUNI}

\section{INTRODUÇÃO}

Todos que conseguem ingressar no ensino superior percorrem um longo caminho até alcançá-lo. No Brasil contemporâneo, entretanto, razões estruturais impedem que grande parcela da população consiga avançar, mesmo no nível do ensino fundamental. Dados do Instituto Brasileiro de Geografia e Estatística - IBGE, segundo o censo do ano de 2000, mostram que 6,69\% do total da população brasileira, cerca de 11.359.494 pessoas com 17 anos de idade ou mais, dentre as quais, 5.384.355 homens e 5.975.136 mulheres, nunca estiveram em uma escola. Se ampliarmos a faixa etária e alcançarmos os 10 anos de idade, teremos 16.410 .281 de pessoas, ou 9,66\% de pessoas que declararam não saber ler nem escrever. No ensino médio a situação é mais grave, pois o número de concluintes deste nível educacional é mínimo em relação ao que ingressou. Ainda no mesmo censo, o IBGE apresenta os dados do ensino superior no país: são 5.890 .631 de pessoas, onde 2.689 .726 são homens e 3.200 .905 são mulheres, configurando um percentual de apenas $3,46 \%$ do total populacional no país, atendido neste nível de ensino.

\section{1 - O ACESSO AO ENSINO SUPERIOR PELO ProUni}

O Programa Universidade para Todos, o ProUni, é um programa do Ministério da Educação - MEC, criado pelo Governo Federal no ano de 2004, e que tem como finalidade a concessão de bolsas de estudo integrais e parciais em instituições de educação superior privadas, em cursos de graduação e sequenciais de formação específica, a estudantes brasileiros e de baixa renda que não possuem diploma de nível superior. Criado pela Medida Provisória no 213/2004 e institucionalizado pela Lei no 11.096, de 13 de janeiro de 2005, o ProUni oferece, em contrapartida, a isenção de alguns tributos àquelas instituições que aderirem ao programa.

No seu primeiro processo seletivo, no segundo semestre letivo do ano de 2005, o ProUni ofereceu 112.275 bolsas, sendo 71.905 integrais e 40.370 parciais, em 1.142 instituições de ensino superior de todo o país. As bolsas parciais oferecem o desconto de $50 \%$ do valor da mensalidade e, na modalidade integral, o estudante tem isenção total da mensalidade. Para a bolsa integral, enquadram-se os candidatos que possuam renda familiar, per capita, de até um salário mínimo e meio. Já a bolsa parcial, que propicia o desconto de $50 \%$ nas mensalidades é destinada aos candidatos que possuam renda familiar, per capita, de até três salários mínimos. No ano de 2011 ofereceu 254.598 bolsas, sendo 129.672 integrais e 124.926 parciais em todo o país.

Só pode candidatar-se ao ProUni o estudante que tiver participado do Exame Nacional do Ensino Médio, o ENEM, que é realizado anualmente, e se nele obteve a nota mínima de 45 pontos, estabelecida pelo Ministério da Educação como resultado da média aritmética entre as provas de redação e conhecimentos gerais. Os resultados do ENEM são usados como critério para a distribuição das bolsas de estudos, isto é, as bolsas são distribuídas conforme as notas obtidas no ENEM pelos estudantes. Assim, os estudantes que alcançarem as melhores notas no exame terão maiores chances de escolher o curso e a instituição em que estudarão. Além da nota mínima de 45 pontos, no ENEM, e das condições quanto à renda familiar, é necessário que o candidato satisfaça uma das condições a seguir: ter cursado o ensino médio completo em escola pública; ou ter cursado o ensino médio completo em escola privada com bolsa integral; ou ter cursado todo o ensino médio parcialmente em escola da rede pública e parcialmente em 
instituição privada, na condição de bolsista integral da respectiva instituição; ou ser portador de deficiência; ou ainda, ser professor da rede pública de ensino básico, em efetivo exercício, integrando o quadro permanente da instituição e concorrendo a vagas em cursos de licenciatura, normal superior, ou pedagogia. Neste último caso, a renda familiar por pessoa não é considerada.

O ProUni reserva bolsas aos cidadãos portadores de deficiência e aos autodeclarados pretos, pardos ou índios. O percentual de bolsas destinadas aos cotistas é igual àquele de cidadãos pretos, pardos e índios, por Unidade da Federação, segundo o último censo do IBGE. Ainda, o candidato cotista também deve se enquadrar nos demais critérios de seleção do programa. O programa prevê também vagas para os professores da Educação Básica Pública.

Mesmo com estas possibilidades, se o estudante selecionado com uma bolsa parcial não puder pagar a outra metade da mensalidade, o MEC possibilita a este bolsista $1 / 4$ do valor total da mensalidade por meio do FIES - Fundo de Financiamento ao Estudante do Ensino Superior. Assim, o estudante pagará os $25 \%$ restantes do valor total da mensalidade enquanto estiver estudando. E, após sua formatura é que dará início ao pagamento do valor financiado.

Desde a sua primeira edição o Programa Universidade para Todos, o ProUni ofertou um total de 1.383.318 bolsas em todo o país. O Rio Grande do Norte vem participando desde a primeira edição do ProUni. Até o primeiro semestre do ano de 2012, foram ofertadas 24.803 bolsas de estudo no estado. 0 Estado iniciou sua participação no ProUni em apenas duas cidades: Natal e Mossoró. Neste ano, faculdades em nove cidades ofereceram bolsas, são elas: Açú, Caicó, Currais Novos, Goianinha, Mossoró, Natal, Nova Cruz, Parnamirim e Santa Cruz.

\section{2 - PERCURSO TEÓRICO METODOLÓGICO}

\subsection{A Teoria das Representações Sociais}

As representações tornaram-se objeto de estudo, nas ciências humanas, a partir do interesse do sociólogo francês Émile Durkheim, em 1912, em conhecer "o aspecto essencial e permanente da humanidade", quando concebe a noção de representações coletivas onde indivíduo e sociedade estariam dissociados. Essas representações, para ele, teriam leis e natureza próprias distinguindo-as das representações individuais. Isso ficou claro com a publicação de As formas elementares da vida religiosa onde a investigação das práticas religiosas das tribos de sociedades primitivas australianas marcou o princípio do estudo das representações. Conforme Nóbrega (2001, p.57),

O sociólogo francês classifica e opõe as representações coletivas às representações individuais considerando que o pensamento social possui uma matéria e estados específicos que somente podem ser interpretados por fatores outros. Para ele, as representações coletivas têm suas leis próprias e pertencem a uma outra natureza, que é diferenciada do pensamento individual.

Com base nos estudos empreendidos por Durkheim é que Moscovici concebe a Teoria das Representações Sociais em 1961, na França, tornada pública com a pesquisa $A$ Psicanálise, sua imagem $e$ seu público. O que há de diferente na representação defendida por Moscovici (1961) é a supressão da dicotomia entre indivíduo/sociedade, sujeito/objeto.

A Teoria das Representações Sociais formulada no final dos anos 50 deste século se apresenta como proposição de uma démarche epistemológica de interpretação da realidade quotidiana da vida moderna. Ela marca uma nova etapa na história da psicologia, à medida que opera uma ruptura com os "modelos funcionalistas" e positivistas ainda em vigor nessa época. É por sua proposição em pensar o homem e os acontecimentos sociais, invertendo os princípios e a 
ordem do conhecimentos psicológico até então estabelecidos, que a teoria das representações sócias vai encontrar resistência, notadamente, entre os paradigmas dos saberes dominantes na época - o behaviorismo e o "marxismo de tipo mecanicista". (NÓBREGA, 2001, p. 58-59)

Diferentemente da teoria difundida por Durkheim onde as representações coletivas estão separadas, dissociadas das representações individuais (NÓBREGA, 2001), a Teoria das Representações Sociais leva em consideração a interpenetração das representações coletivas e individuais. Nessa teoria não há a separação entre indivíduo e sociedade, sujeito e objeto. É uma nova abordagem das representações pois, diferentemente da psicologia social americana/behaviorista, onde a representação tem caráter estático, na Teoria das Representações Sociais a representação é dinâmica, tem movimento de elaboração e estruturação ( $\mathrm{MOSCOVICl,} \mathrm{2003).} \mathrm{Tem-se} \mathrm{então} \mathrm{um} \mathrm{instrumento} \mathrm{de} \mathrm{transformação} \mathrm{da}$ realidade, um processo de construção e reconstrução, logo, dinâmico.

As representações sociais são definidas, por Moscovici (1978), como "um conjunto de conceitos" que são construídos no percurso das relações sociais mantidas pelo sujeito na coletividade, partindo do senso comum, salientando o papel das comunicações interpessoais, na (re)construção das representações sociais.

A Teoria das Representações Sociais visa investigar, conhecer como são interpretados dentro dos grupos os saberes populares, o senso comum, as crenças, a partir das comunicações intra-grupos. Moscovici levou, assim, o saber do senso comum a ter status de forma do pensamento/concepções humanas, uma zona de partilhamento. Um "lugar onde foram geradas as representações sociais, não onde o conhecimento científico foi corrompido e distorcido" (MOSCOVICl apud NÓBREGA, 2001, p.63). As representações sociais têm como característica importante a dinamicidade. Não é um conceito estático, pronto e acabado. Permite-se e reconfiguração de análises e conceitos para a redefinição de ideias e definições. As representações sociais são "um conjunto de conceitos, proposições e explicações originados na vida cotidiana no curso de comunicações interpessoais." (MOSCOVICl apud OLIVEIRA; WERBA; 1998, p.106)

A representação social se utiliza, para fins conceituais, de dados ou elementos do senso comum, da internalização de novos conhecimentos, das práticas cotidianas de um determinado grupo, da observação dos fenômenos coletivos. (MOSCOVICl, 1978). Deste modo, um processo de identificação aos códigos comuns ao grupo de pertencimento, transcorre no convívio social, na observação dos discursos circulantes e ações praticadas. Passeggi (2003) chama atenção para a linguagem verbal como elemento constitutivo das representações sociais, pois enquanto epistemologia do conhecimento do senso comum e da produção de sentidos, as representações sociais enraízam-se na plasticidade constitutiva da linguagem e na dinamicidade das interações sociais.

Registramos também aqui a observação de Oliveira e Werba (1998), que consideram as representações sociais como um recurso para tornarmos o não familiar conhecido, familiar. Com base em Moscovici, as autoras enfatizam dois universos distintos de pensamento: os Concensuais e os Reificados. No primeiro, estão inseridas as ações cotidianas, o senso comum, as representações sociais. No segundo, a abstração teórica, as ciências. O familiar estaria ligado aos Universos Concensuais e o não familiar aos Universos Reificados.

[...] por Representações Sociais entendemos um conjunto de conceitos, proposições e explicações [...] Elas são o equivalente, em nossa sociedade, aos mitos e sistemas de crenças 
das sociedades tradicionais; podem também ser vistas como a versão contemporânea do senso comum. (MOSCOVICl apud OLIVEIRA; WERBA; 1998, p. 106)

Pelo exposto, constata-se que o conhecimento popular do senso comum é o objeto de observação e investigação da Teoria das Representações Sociais. As relações compartilhadas socialmente, publicamente por um grupo, possibilitam a seus constituintes criar categorias para objetos sociais que podem provocar a ressiginificação de um conceito. Tal ressignificação é efetivada no seio de grupos sociais - nesta pesquisa, os ingressantes na universidade.

O ProUni, enquanto política social a partir de renúncia fiscal em favor de instituições privadas de ensino superior, observado em nossa pesquisa, que tem duas vertentes de alimentação da representação, no nível de sua emergência, sendo uma moral e a outra social. A moral lança pressuposições sobre o ProUni, na medida em que o analisa, julga e valoriza como acesso privilegiado para alguns. A social comporta, percepções variadas e contraditórias, como o apoio de conhecimentos justificados, de acadêmicos, pesquisadores, jornalistas, políticos, gestores públicos e formadores de opinião em geral.

\subsection{Contextualizando a pesquisa: os participantes e suas origens}

À primeira vista pode-se pressupor que os alunos participantes da pesquisa façam parte da parcela privilegiada da população, cuja realidade é bem diferente da grande parte dos brasileiros que não têm acesso ao Ensino Superior. Mas decidimos investigar mais minuciosamente a questão: será que, ainda que ali chegado, teriam eles sofrido percalços na sua história de formação educacional? Teriam eles diferentes perspectivas, interpretações, e/ou expectativas em relação ao ensino superior? O que os trouxe até ali? Quais os custos da sua persistência? Que repercussão teve na vida familiar e profissional o ingresso no ensino superior? Quem são e o que pensam estes estudantes que foram alçados a um patamar privilegiado da população?

Com a nova forma para ingresso no ensino superior, através do ProUni, percebemos a importância em pesquisar este novo contingente da educação superior brasileira. E fazer o estudo é de suma importância para um acompanhamento desta representação, pois, com base em transformações que poderão ocorrer, será possível balizar o planejamento, tanto no nível pedagógico como no nível da gestão pública.

A pesquisa foi realizada em uma instituição de ensino superior da rede privada de ensino, localizada na zona sul de Natal-RN, com o objetivo de identificar as representações sociais de universidade entre os sujeitos investigados. Participaram da análise os textos e respostas de 80 alunos recém-admitidos ao Ensino Superior através do processo seletivo do ProUni. Os estudantes eram de 03 diferentes cursos.

A coleta de dados foi feita através de dois procedimentos: aplicação da técnica de Associação Livre de Palavras, e elaboração, pelos sujeitos, de um texto dissertativo intitulado Universidade. A aplicação dos procedimentos foi realizada em momentos distintos para evitar que uma oferecesse influência sobre a outra.

As diferentes cidades de origem dos participantes da pesquisa são em um total de 17: Afonso Bezerra, Canguaretama, Ceará-Mirim, Frutuoso Gomes, Goianinha, João Câmara, Macaíba, Macau, Monte Alegre, Natal, Nova Cruz, Parnamirim, Santa Maria, São Gonçalo do Amarante, Serra Caiada, Sítio Novo e Vera Cruz. Vale salientar que aqui a origem não tem a conotação de naturalidade - município onde o indivíduo nasceu, mas a residência familiar desses alunos. Esta ressalva se faz necessária pois grande parte dos alunos, e particularmente os que 
ingressam através do ProUni, reside com seus pais/familiares em cidades que distam da capital, o que inviabiliza o seu deslocamento diário. Por este motivo passam a residir temporariamente na capital por vezes durante a semana, retornando ao seu endereço de origem nos finais de semana e feriados.

\subsection{Procedimentos para o levantamento de dados}

A abordagem teórico-metodológica escolhida foi a associativa (ABRIC, 1998), pela sua pertinência e propriedade com os pressupostos aqui assumidos, pois concordamos com o referido autor, que, para o acercamento à dimensão simbólica do objeto de estudo é necessário superar a pergunta direta, a abordagem interrogativa. Abric afirma também que, em resposta a perguntas explícitas, o pesquisador obtém mais facilmente opiniões do que representações. Além do mais, a própria opção pelo recorte do campo simbólico nos direciona para a mínima intervenção do pesquisador e a máxima subjetividade do sujeito, daí a escolha pela Associação Livre de Palavras. Aquela técnica, projetiva, tem o objetivo de suscitar ideias por meio da audição de um termo indutor, cuja finalidade é desencadear livres ideias a respeito de um tema específico. Pressupõe-se que as evocações estão associadas ao tema gerador e podem fazer emergir seu campo semântico, reduzindo as possibilidades de racionalizações e revelando conteúdos latentes, mais próximos ao campo representacional do objeto de estudo.

$\mathrm{O}$ ato de evocar propicia um chamamento às memórias do subconsciente. Essas memórias, embora não estejam na superfície, no consciente humano, encontram-se encobertas, em estado de latência. Inconscientemente, elas influenciam seus comportamentos e, num momento de estímulo, podem emergir ao domínio da consciência. De acordo com Rosa (2005, p. 64) “[...] atribui-se particular importância à técnica de associação livre, devido à sua relevância informativa e autenticidade no processo de resposta, e também pela sua simplicidade de utilização.".

A coleta foi realizada no ambiente de estudos dos alunos participantes e a aplicação da técnica consistiu em solicitar aos sujeitos que escrevessem, na ficha entregue a eles, as três palavras que lhes viessem primeiramente à mente em relação ao termo referido. Após a inscrição das palavras foi solicitado que enumerassem de 1 a 3 a ordem de importância e/ou força em relação à palavra indutora. Finalmente, foi pedido que justificassem a que consideraram mais importante. Essa técnica de coleta de dados permite colocar em evidência o universo semântico do objeto estudado, assim como a sua dimensão imagética de forma mais rápida e dinâmica de diferentes outros métodos. Em outra ocasião, os sujeitos foram convidados a fazer uma redação sobre o tema universidade. Todo texto dissertativo aborda um tema, ou seja, a delimitação de um assunto. Sendo assim, solicitamos que eles, considerando ensino superior como um tema, a partir do título Universidade. escrevessem uma redação clara e coerente.

As palavras redação e dissertação têm em sua significação grande proximidade. De acordo com diferentes dicionários ${ }^{1}$, a redação é o ato de redigir, arte ou maneira de redigir; e que redigir significa escrever organizadamente e com metodologia. A palavra dissertação tem como significado o ato de expor, através da escrita ou da oralidade, as compreensões sobre qualquer assunto. Neste documento optamos pelo uso da expressão redação, que no léxico cotidiano remete à ideia mais ampla de expor a compreensão sobre algo; já a palavra dissertação está, no uso cotidiano, semanticamente mais próxima de um tipo específico de redação - o documento final da pós-graduação em nível de mestrado. Assim como tese remete ao documento final de um doutorado, e não à ideia geral de argumento.

${ }^{1}$ Dicionários eletrônicos ou on-line Aurélio, Houaiss e Priberam. 


\subsection{Procedimentos de Análise dos Dados}

Como afirmamos, o recorte epistemológico do campo simbólico requereu técnicas de coleta com a mínima intervenção do pesquisador, motivando-nos a escolher a Associação Livre de Palavras e a redação. Como consequência, escolhemos para as análises as técnicas e softwares a seguir descritos, pela sua compatibilidade com dados gerados por processos associativos e com os objetivos do estudo: acessar o universo representacional dos sujeitos, para além das respostas objetivas.

Análise das Associações Livres: Para o tratamento dos dados coletados através da Associação Livre de Palavras, foi utilizado o EVOC, versão 2000, que é um software de análise de dados textuais que possibilita a identificação de expressões e palavras de uso comum, que servem de base para as representações da comunidade acerca do aspecto estudado.

O produto das evocações, as três palavras, foi organizado previamente, constituindo-se em um corpus para análise nesse programa. O material foi, então, tratado pelo software, que calculou para o conjunto do corpus a frequência simples de cada palavra evocada, as ordens médias de evocação de cada palavra e a média das ordens médias de evocação.

Análise das justificativas das associações: As justificativas inicialmente foram analisadas pelo programa ALCESTE, pois foi nossa intenção restringir ao mínimo possível a subjetividade do pesquisador. Entretanto, não logramos êxito com a aplicação do referido software, tendo em vista que as falas deste procedimento costumam ser breves, resultando em arquivos aquém da extensão necessária requerida pelo programa.

Partimos então para a análise de conteúdo, cuja origem está na Linguística, tendo como objeto de estudo a palavra. Na pesquisa ora apresentada, o enfoque semântico favoreceu a compreensão dos significados, os aspectos sociais e psicológicos, e, como nos diz Bardin (1995, p. 44), um ícone deste tipo de análise nas ciências sociais e da comunicação: "a análise de conteúdo é uma busca de realidades subjetivas através das mensagens".

Análise das redações: Para análise do corpus da pesquisa relativo à redação foi utilizado o programa informático ALCESTE 4.5, que permite a análise dos conteúdos através da Análise Lexical de um Conjunto de Segmentos de Textos. Esse programa é um software produzido na França, que possibilita o exame quantitativo dos casos apresentados, e tem a possibilidade de identificar, nos textos produzidos pelos sujeitos, as palavras e os trechos que conferem coerência às ideias neles contidas. Ele agrupa os dados, conforme a lista de palavras oriundas dos relatos escritos, lê e interpreta dos referidos relatos por meio de análises mais refinadas.

\subsection{Análises da Associação Livre de Palavras pelo software EVOC}

$\mathrm{Na}$ Associação Livre de Palavras, cada sujeito citou 3 palavras. Os alunos ingressantes através do ProUni, o produto das palavras evocadas foi em um total de 240 palavras. Destas, 93 foram distintas.

Ao processarmos o elenco de palavras e o número de ocorrências que cada uma obteve, optamos por trabalhar com as que obtiveram a partir de 05 evocações. Desta feita, listamos todas as palavras com ocorrência acima de cinco e organizamos de modo que pudéssemos categorizar de acordo com as técnicas da análise de conteúdo. Conforme Seca (apud ROSA 2005, p. 71), 
A lista de palavras evocadas representam o sistema categorial duma representação. 0 trabalho da análise tem como objectivo a compreensão da natureza e da estrutura das associações através dum número de abordagens: semântica (a síntese dos significados transmitidos a partir de termos induzidos, codificação de sinónimos, metáforas, conotações), temática (criação dum grupo de categorias que permite a classificação de termos induzidos por tema e sub-tema, calculando as suas frequências, co-ocorrências, dispersão, e relação de concordância e contradição), e lexical (o racio dos verbos/adjectivos, os termos mais citados, fluidez verbal, proporção do número de termos diferentes comparado com o número total de termos induzidos).

Para o tratamento destes dados coletados foi utilizado o software EVOC versão 4.0. O produto das evocações, as três palavras, foi organizado previamente, constituindo-se em um corpus para análise nesse programa. O material foi, então, tratado pelo software que calculou, para o conjunto do corpus, a frequência simples de cada palavra evocada, as ordens médias de evocação de cada palavra e a média das ordens médias de evocação.

\begin{tabular}{|c|c|c|c|c|c|}
\hline \multicolumn{3}{|c|}{ NÚCLEO CENTRAL } & \multicolumn{3}{|c|}{ 19 PERIFÉRICO } \\
\hline \multicolumn{3}{|c|}{ Frequência $>=5,0 /$ Rang $<=2,0$} & \multicolumn{3}{|c|}{ Frequência $>=5,0 /$ Rang $<=2,0$} \\
\hline & FREQ & RANG & & FREQ & RANG \\
\hline Aluno & 8 & 1,375 & curso & 6 & 2,333 \\
\hline aprendizado & 6 & 1,667 & diploma & 6 & 2,000 \\
\hline conhecimento & 26 & 1,385 & estudo & 7 & 2,000 \\
\hline educação & 6 & 1,500 & formação & 10 & 2,000 \\
\hline \multirow[t]{4}{*}{ Futuro } & 16 & 1,938 & professor & 5 & 2,600 \\
\hline & & & profissão & 9 & 2,444 \\
\hline & & & realização & 9 & 2,000 \\
\hline & & & sucesso & 9 & 2,111 \\
\hline
\end{tabular}

Fig. № 01 - Gráfico EVOC dos sujeitos ProUni

Legenda

Les 3 colonnes correspondent respectivement :

au Mot

à sa Fréquence

à son Rang Moyen

Le Fréquence minimale des mots est 5

$* * * * * * * * * * * * * * * * * * * * * * * * * * * * * * * * * *$

Cas ou la Fréquence $>=5$ et le Rang Moyen $<2$

aluno $\quad 8 \quad 1,375$

aprendizado $\quad 6 \quad 1,667$

conhecimento $26 \quad 1,385$ Núcleo Central

educação $\quad 6 \quad 1,500$

futuro $16 \quad 1,938$ 


\begin{tabular}{|c|c|c|c|c|}
\hline \multicolumn{5}{|c|}{ Cas ou la Fréquence $>=5$ et le Rang Moyen $>=2$} \\
\hline curso & 6 & \multicolumn{3}{|c|}{2,333} \\
\hline diploma & & 6 & 2,000 & \\
\hline estudo & 7 & \multicolumn{3}{|c|}{2,000} \\
\hline formação & & 10 & 2,000 & 10 Periférico \\
\hline professor & & 5 & 2,600 & \\
\hline profissão & & 9 & 2,444 & \\
\hline realização & & 9 & 2,000 & \\
\hline sucesso & 9 & \multicolumn{3}{|c|}{2,111} \\
\hline \multicolumn{4}{|c|}{ Cas ou la Fréquence $<5$ et le Rang Moyen $<2$} & Complementar \\
\hline \multicolumn{4}{|c|}{ Cas ou la Fréquence $<5$ et le Rang Moyen $>=2$} & 2ㅇ Periférico \\
\hline
\end{tabular}

Os alunos têm o acesso ao ensino superior, e já de início têm expectativas quanto ao produto que vão adquirir quando do momento da formatura, e que como resultado da posse do acesso e do produto, o almejado emprego que conferirá a ele a possibilidade de ser um futuro profissional com trabalho/ emprego/ profissão e que terá como recompensa/pagamento o dinheiro. Esses dados foram inseridos no software EVOC 4.0, que nos apresentou sua análise.

Observe-se que o Núcleo Central está configurado por palavras que têm categorias que podem ser arranjadas em ordem de construção. Os instrumentos que permitem a elaboração do processo estão representados pela palavra aluno. Os produtos do processo que geram expectativas são representados pelas evocações de aprendizado, conhecimento e educação. E, para os benefícios almejados que serão alcançados após a concretização do processo estão no futuro.

No núcleo 1 o periférico, estes estão situados no quadrante superior direito, podemos visualizar as evocações curso, diploma, estudo, formação, professor, profissão, realização e sucesso. Nesse caso, segundo Vergés (1992) há uma proximidade entre estas evocações e as que estão localizadas no quadrante superior esquerdo. Vemos que os produtos do processo têm destaque através do diploma, da realização e do sucesso. Os benefícios almejados estão aqui representados pela profissão. Mas, não sem antes ter passado pelo processo de estudo e formação e, para tal, depende dos instrumentos dentre os quais o professor tem grande importância no decorrer do processo.

\subsection{Análise de Conteúdo das Justificativas das palavras evocadas}

A técnica de Associação Livre de Palavras requer de cada sujeito uma justificativa, na qual ele pode explicitar as relações intrínsecas entre aquelas palavras, bem como a ordenação que deu a elas. As análises destas justificativas dos sujeitos foram realizadas seguindo as orientações de Bardin (1995), iniciando-se pela pré-análise, com as seguintes regras: 1 - da exaustividade momento onde a leitura cuidadosa do corpus permite o alcance dos pormenores existentes; 2 da representatividade - respeitando-se a amostra representativa do universo pesquisado; 3 - da homogeneidade e de pertinência - onde os documentos para análise seguiram a critérios idênticos e precisos.

Após a análise propriamente dita inicia-se com a categorização, sendo uma das formas a investigação dos temas, para defini-los a partir de critérios previamente estabelecidos. Nesse estudo, adotamos o critério semântico, buscando identificar temas e compatibilizá-los com as categorias do EVOC.

Para Bardin (1995), são qualidades de uma boa categoria: a exclusão mútua, a homogeneidade, a pertinência, a objetividade, a fidelidade e a produtividade. No caso desta pesquisa, estes critérios foram buscados, porém o fiel da balança para nos satisfazer quanto à eficácia das categorias já estava posto e era 
os agrupamentos de palavras obtidos pelo EVOC. Esta é nossa compreensão, salvo melhor juízo, no nosso papel de pesquisador em busca da coerência entre os procedimentos adotados, num desenho plurimetodológico de pesquisa. Entendemos pois não ser pertinente uma disputa entre os critérios preconizados por Bardin e o gráfico do EVOC. Ao contrário, nos pareceu mais sensato procurar a correspondência ora descrita. Nos quadros a seguir apresentamos as palavras evocadas com as suas respectivas ocorrências agrupadas nas categorias em que as classificamos.

O primeiro campo semântico denominamos acesso à universidade, pois engloba palavras que traduzem sentimentos e significados relacionados com o acesso ao nível superior de ensino: oportunidade - 14; sonho - 12; conquista - 09; necessário - 07; superior - 06; importante - 06.

Subdividimos o segundo campo semântico em dois, pois embora ambos agrupem palavras que se referem ao cotidiano de uma universidade, ao processo pelo qual se evolui do vestibular à formatura, verificamos que, no 2.1, estas palavras enfocam estratégias do processo: estudo - 28; curso - 13; ensino - 12; crescimento - 09; objetivo - 06; dedicação - 06; desenvolvimento - 05; aprender - 05.

Já o campo 2.2 refere-se a recursos deste mesmo processo, tanto os materiais como os humanos - os personagens do ensino-aprendizagem, seus papéis precípuos na relação institucional e qualidades necessárias aos seus desempenhos. Palavras evocadas e seu número de ocorrências: professor - 26; aluno - 16; amigos - 09; profissionalismo - 08; responsabilidade 08; livros - 07; amizade - 07; e felicidade - 05.

A seguir, destacamos o campo semântico que chamamos de produto acadêmico, por apresentar as evocações que traduzem expectativas e resultados obtidos com a conclusão do ensino superior: conhecimento - 80; formação - 24; aprendizado - 22; educação - 13 ; diploma 11 ; cultura - 08 ; capacitação - 07; sabedoria - 06 ; formatura - 05 ; profissional - 05.

O último campo semântico também se refere a resultados decorrentes da conclusão do ensino superior, mas com maior amplitude, isto é, as palavras nele reunidas referem-se a ganhos sociais mais gerais que o grau ou diploma; para além do conhecimento, da formação e do aprendizado. As palavras deste campo nos remetem ao idealizado futuro - 55 , que comporta sucesso - 36 e realização - 26; emprego - 10, trabalho - 06 e dinheiro - 06.

\subsection{Análise das redações pelo software ALCESTE}

O corpus da pesquisa foram as redações dos sujeitos ingressantes pelo processo seletivo ProUni. Foi submetido ao ALCESTE - Analyse Lexicale par Contexte dum Ensemble de Segments de Texte (REINERT, 1990), que apresentou os resultados que ora expomos. O programa tem como critério de definição das palavras a sua frequência média (palavras maior que $n$ ), que é o critério lexicográfico realizado pelo software na operação A2. Em seguida, a partir das palavras com frequência igual ou superior à média de $x^{2}>3,84$, o teste estatístico é realizado com grau de liberdade igual a 1.

\begin{tabular}{|l|r|}
\hline \multicolumn{1}{|c|}{ Operações } & Valores \\
\hline A2: Calcul du dictionnaire & 2520 \\
\hline Nombre de formes distinctes & 14564 \\
Nombre doccurrences & 6 \\
Fréquence moyenne par forme & 1428 \\
Nombre de hapax & 675 \\
Fréquence maximum dune forme & 3000 \\
\hline A34 : Fréquence maximale dun mot analysé & \\
\hline
\end{tabular}


Nombre de mots analysés

Nombre de mots supplémentaires de type " $r$ "

Nombre de mots supplémentaires de type " $s$ "

Nombre doccurrences retenues

Moyenne par mot

Nombre doccurrences analysables (fréq.> 3)

5.376088

Nombre doccurrences supplémentaires

Nombre doccurrences hors fenêtre fréquence

8846 soit $75.374920 \%$

Quadro № 01 - Resumo das operações realizadas pelo ALCESTE sobre as redações dos ingressantes ProUni

Legenda: Projection des mots analyses sur le plan 12 (corrélations);

Axe horizontal : 1e facteur : V.P. =.1877 (45.17\% de linertie) ; Axe vertical : 2e facteur : V.P. =.1292 (31.09\% de linertie)

\begin{tabular}{|c|c|}
\hline Classes & D1: Distribuição das palavras da forma original por raiz \\
\hline \multirow{3}{*}{ Classe 1} & aprend+ : aprende(3), aprender(10); \\
\hline & cresc+: $\operatorname{crescer}(7)$ \\
\hline & cultur<: cultura(1), culturais(2), cultural(2), culturas(1); \\
\hline \multirow{2}{*}{ Classe 2} & aluno+ : aluno(7), alunos(11); \\
\hline & professor+ : professor(1), professores(7); \\
\hline \multirow{3}{*}{ Classe 3} & profission+ : profissionais(18), profissional(28); \\
\hline & conhecimento+: conhecimento(26), conhecimentos(20); \\
\hline & sociedade+ : sociedade(22); \\
\hline \multirow{3}{*}{ Classe 4} & bolsa+ : bolsa(3), bolsas(5); \\
\hline & faculdade+ : faculdade(8), faculdades(6); \\
\hline & escola+ : escola(5), escolas(5); \\
\hline
\end{tabular}

\section{Quadro № 02 - Agrupamento das palavras em classes/contextos}

Constata-se que as palavras agrupadas pelo ALCESTE na classe 1 referem-se ao objetivo de ingressar no ensino superior; na classe 2 estão as palavras referentes ao processo ensinar/aprender e seus atores; já a classe 3 reúne palavras relacionadas aos produtos do estudo; enfim, a classe 4 contém palavras que remetem a algumas condições para estudar.

Dendrogramme des classes stables (à partir de B3 rcdh1)
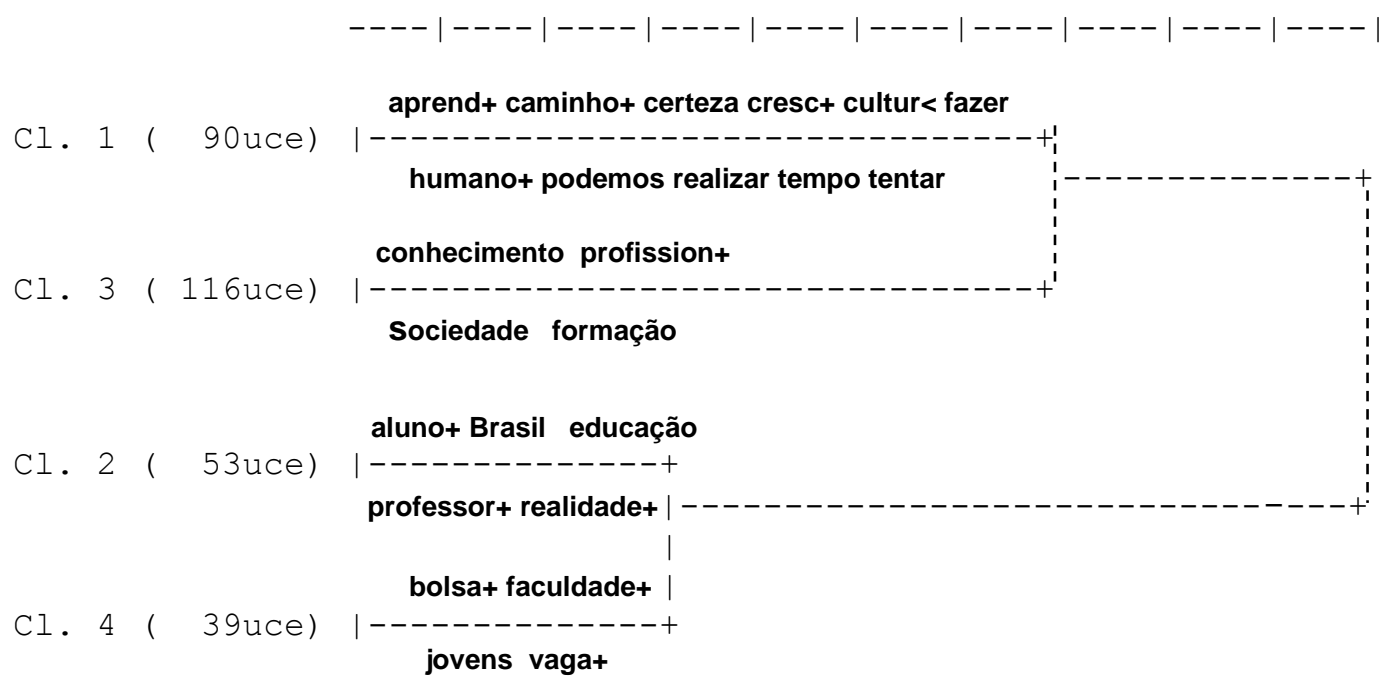

Fig. № 02 - Classificação Hierárquica Descendente 
O corpus da pesquisa que compreende os textos produzidos pelos alunos, foi dividido em 298 unidades de contexto elementar (UCEs). De acordo com o contexto das UCEs, foram delineadas 04 classes. Assim, as classes 1 e 3 se apresentam com o total de 206 UCEs, ou 69,13\% do total; e as classes 2 e 4 se apresentam com o total de 92, ou 30,87\% da totalidade desse corpus.

\begin{tabular}{|l|c|c|}
\hline \multicolumn{1}{|c|}{ Palavra } & Frequência & $\mathrm{X}^{2}$ \\
\hline aprend+ & 11 & 13.94 \\
\hline caminho+ & 7 & 6.06 \\
\hline Certeza & 8 & 15.16 \\
\hline cresc+ & 7 & 12.80 \\
\hline cultur< & 6 & 10.48 \\
\hline fazer & 11 & 7.38 \\
\hline humano+ & 7 & 4.69 \\
\hline podemos & 11 & 16.30 \\
\hline realizar & 6 & 7.83 \\
\hline tempo & 9 & 9.82 \\
\hline tentar & 7 & 9.96 \\
\hline
\end{tabular}

\section{Quadro № 03 - Frequência e Qui-quadrado das Palavras da Classe 1}

Classe $\mathrm{n}^{\circ} 1$ => Contexte $\mathrm{A}$

Nombre du.c.e.:90. soit : $30.20 \%$

Nombre de "uns"(a+r):2191. soit : $28.97 \%$

Nombre de mots analysés par uce : 19.86

Conforme os critérios já expostos, o ALCESTE listou na operação A2 palavras que denotam a construção de uma forma de proceder: aprend+, caminho+, certeza, cresc+, cultur<, fazer, humano+, podemos, realizar, tempo, tentar. É possível visualizarmos através destas palavras a elaboração: "A universidade é o caminho da cultura onde nós temos a certeza de que podemos aprender e crescer através do fazer humano e sempre há tempo para tentar realizar.".

A esta classe está associada à noção de processo, de construção. Dela fazem parte os sujeitos que têm a universidade como o caminho para a conquista do sucesso: aprend+, caminho+, certeza, cresc + , cultur<, fazer, humano+, podemos, realizar, tempo, tentar. Os textos que obtiveram destaque nessa operação na classe 01 , com 90 unidades de contexto elementar (UCEs) e que compreendem $30,20 \%$ no total de UCEs, foram aqueles que trataram da universidade como caminho para a aprendizagem, que superaram o tempo de espera para alcançar o sonho e também tempo de dedicação e realizações:

[...] Hoje me sinto vitoriosa, pois vou aprender mais, conhecer pessoas do mesmo ideal, mesmo nível, em que possamos trocar ideias e com isto enriquecer cada vez mais trocar os conhecimentos. No mundo de hoje em que muitos se acomodam entrar para uma universidade é dizer não à mesmice, é subir mais um degrau é tentar minimizar a distância entre nós e aqueles que estão num patamar mais alto. Portanto, o meu desejo é continuar subindo os degraus da vida para poder também transmitir tudo aquilo que aprender para outras pessoas [...] para que pessoas através de mim possam também aprender e realizar os seus ideais e dar continuidade a este processo de ensino aprendizagem para que haja uma sociedade melhor. (suj 046 cur 01 sex 02 ). 
A universidade para mim é o caminho do sucesso profissional que nem todas as pessoas que chegam à universidade percorrem esse caminho. Na minha vida, por exemplo, a universidade é o caminho que eu vou percorrer para chegar ao topo do sucesso profissional. [...] A universidade é o caminho do sucesso. (suj 282 cur 01 sex 01 ).

\begin{tabular}{|l|c|c|}
\hline \multicolumn{1}{|c|}{ Palavra } & Frequência & $\mathrm{X}^{2}$ \\
\hline aluno+ & 14 & 10,82 \\
\hline Brasil & 9 & 17,11 \\
\hline Educação & 16 & 34,93 \\
\hline professor+ & 6 & 5,33 \\
\hline Realidade & 8 & 12,00 \\
\hline
\end{tabular}

\title{
Quadro № 4 - Frequência e Qui-quadrado das Palavras da Classe 2
}

\author{
Classe $\mathrm{n}^{\circ} 2$ => Contexte $\mathrm{B}$ \\ Nombre du.c.e. : 53 . soit : $17.79 \%$ \\ Nombre de "uns" (a+r): 1371. soit : $18.13 \%$ \\ Nombre de mots analysés par uce: 21.66
}

Os textos agrupados pelo ALCESTE na classe 02 têm 53 unidades de contexto elementar (UCEs), que compreendem $17,79 \%$ no total de UCEs. Nesta classe foram expressos os agentes principais de todo o processo de formação acadêmica, no contexto social no país. Assim, aluno+, professor+, educação, realidade e Brasil, são peças de um quebra-cabeças cujo tema é uma realidade difícil, tanto pela busca da formação profissional quanto pelo direito ao ensino público e gratuito.

Os excertos a seguir tiveram destaque na análise do software ALCESTE, do arquivo REDAÇÃO nesta classe 02 estão os que tratam da força de vontade em aprender e ter acesso a novos conhecimentos, no ambiente da universidade. O primeiro deles foi elaborado por uma aluna do curso de administração.

[...] O Brasil é um país subdesenvolvido, esse status se deve, além de outros fatores, ao grau de educação de seu povo. [...] A educação básica oferecida pela rede pública geralmente contém muitas falhas. Falta de professor, acesso a escola dificultado, trabalho infantil que ronda a realidade de muitas crianças em todo o país, são alguns dos fatores responsáveis pelo mau desempenho dos alunos na educação básica que vai refletir no acesso a Universidade. Muitos estudantes, devido a essas descritas, entre outras condições básicas que lhes faltam para terem acesso a uma educação de qualidade, não conseguem nem mesmo concluir o Ensino médio, último degrau da educação básica nem tão pouco alcançarem o Ensino Nível Superior, sendo, engolido, pela forte competição existente em torno do acesso a carreira acadêmica. Não basta garantir o direito a educação, esse precisa ser através de condições humanas dignas de sobrevivência. Uma coisa é certa, o Brasil está evoluindo [...] educação é o melhor caminho para o desenvolvimento, mas é difícil aprender com fome, com sede, sujo e sem ter onde dormir, portanto sem condições de viver é difícil aprender. (suj 079 cur 01 sex 020). 


\begin{tabular}{|l|c|c|}
\hline \multicolumn{1}{|c|}{ Palavra } & Frequência & $X^{2}$ \\
\hline conhecimento+ & 39 & 24,29 \\
\hline Formação & 18 & 23,52 \\
\hline profission+ & 41 & 30,56 \\
\hline sociedade+ & 18 & 14,29 \\
\hline
\end{tabular}

\section{Quadro № 5 - Frequência e Qui-quadrado das Palavras da Classe 3}

Classe $\mathrm{n}^{\circ} 3=>$ Contexte $\mathrm{C}$

Nombre du.c.e.: 116 . soit : $38.93 \%$

Nombre de "uns"(a+r):2972. soit: $39.29 \%$

Nombre de mots analysés par uce: 20.61

Nesta classe, a operação A2 apresentou as palavras conhecimento+, formação, profission+ e sociedade+ que dizem respeito a 38,93\% do total das UCEs, que são 116 unidades de contexto elementar (UCEs). Aqui é possível observar que a sociedade poderá ou não ser receptora daqueles que através do conhecimento têm acesso à formação profissional. Nos textos destacados pelo ALCESTE, os sujeitos demonstram a consciência do papel de todos para que sua formação tenha significado e que possa trazer o retorno esperado, que é a sua formatura.

A universidade é o campo de formação social, profissional e muitas vezes pessoal. Partindo dessa concepção podemos concluir que a universidade, como o enunciado da palavra já explícito, constitui o conjunto formador do cidadão, ou seja, a universidade abrange e ocupa o topo do conhecimento. [...] é ela que possibilita ás pessoas a ter uma visão mais ampla da sociedade em geral, ou seja é ela que quem prepara o indivíduo para conviver em sociedade, a ter um bom relacionamento social, embora a educação básica seja a responsável a encaminhar as pessoas ás sociedade. A segunda condição, formação profissional é talvez, o principal objetivo de universidade, pois é através dela que se estuda mais amplamente, uma determinada área de conhecimento, ou seja, é através dela que se estuda para adquirir e exercer uma área profissional. A terceira concepção, formação pessoal, é também um dos princípios da universidade, pois além de preparar o indivíduo para ter um bom relacionamento social e uma determinada profissão, ela também possibilita o indivíduo de ter um pensamento convicto, formular hipótese, se auto avaliar. Enfim, possibilita o indivíduo de desenvolver o seu senso crítico o que não acontece, tão frequentemente, na educação básica. (suj 222 cur 01 sex 01).

\begin{tabular}{|l|c|c|}
\hline \multicolumn{1}{|c|}{ Palavra } & Frequência & $\mathrm{X}^{2}$ \\
\hline bolsa+ & 7 & 47,61 \\
\hline faculdade+ & 13 & 30,20 \\
\hline jovens & 9 & 37,67 \\
\hline vaga+ & 10 & 39,86 \\
\hline
\end{tabular}

\section{Quadro № 6 - Frequência e Qui-quadrado das Palavras da Classe 4}

Classe $\mathrm{n}^{\circ} 4$ => Contexte $D$

Nombre du.c.e.: 39 . soit : $13.09 \%$

Nombre de "uns" $(a+r): 1030$. soit: $13.62 \%$

Nombre de mots analysés par uce: 22.13

Os textos que obtiveram destaque nessa operação, na classe 04, com 39 UCEs e que compreendem $17,79 \%$ do total, bolsa+, faculdade+, jovens e vaga+ expressam a preocupação e decepção 
dos sujeitos com a pouca oferta de vagas nas instituições públicas de ensino superior, que comemoram a oferta de vagas através do ProUni.

Com a escolha de um curso superior, onde cada pessoa jovem ou com mais idade passa quase toda uma vida para ter certeza do que quer fazer profissionalmente. Mas quando ela chega mas esperava no ensino superior algumas podem encontrar muitas decepções como o curso não era como esperava ser, professores que começam a encrencar com a pessoa, entre várias outras coisas. Mesmo aquelas pessoas que não se decepcionaram com o curso encontram algumas dificuldades, pois o ensino superior nem sempre é um mar de rosas, e essas mesmas mesmo gostando do curso acabam desistindo ou trancando. $O$ ensino superior, mesmo nem sempre sendo um ma de rosas, tem os seus benefícios com as amizades que as pessoas fazem tanto com os alunos quanto com os professores, trás o bem maior a educação, uma qualificação profissional para ser seguida. Mas infelizmente muitas pessoas não tem acesso ao ensino superior porque a cada ano o vestibular está mais difícil e por não ter vagas suficientes nas universidades federais, surgiram as faculdades particulares, mas mesmo assim ainda não deu conta pois muita gente não tem condições de pagar o ensino superior. E assim vai levando a vida. (suj 451 cur 03 sex 02 ).

Talvez esperássemos que os alunos ingressantes através do ProUni nos apresentassem um discurso que expusesse suas opiniões acerca do programa. No entanto nos parece que, por já haverem conquistado a bolsa, não sentem a necessidade em se deter na objetivação. De acordo com a Teoria das Representações Sociais, estes sujeitos já ancoraram o objeto (ProUni) e a ancoragem predomina sobre a objetivação.

\section{CONSIDERAÇÕES FINAIS}

Ao observarmos os gráficos do EVOC e os compararmos aos do ALCESTE, podemos perceber que um corrobora o outro, não deixando margem de dúvidas quanto os sentidos circulantes entre os sujeitos. Observando os mapas apresentados é possível compreender que estes sentidos remetem ao produto do nível superior de ensino, focado nos resultados esperados, tanto acadêmicos como profissionais.

A universidade vem para ajudar na graduação, e melhorar, os serviços prestados pelas empresas em geral. $\mathrm{Na}$ atualidade, não basta ter um diploma, mas sim ter muito conhecimento na área de trabalho. Por isso procurei uma instituição com esse padrão de qualidade. Como já destaquei não basta diploma tem que ter conhecimento. (suj 006 cur 02).

Conhecimento, palavra tantas vezes evocada, e sempre dentro de um contexto demasiadamente forte: o trampolim para a conquista de vários objetivos. Dentre estes, a conquista da formação, da educação, da formação profissional, do acesso e aceitação pelo mercado de trabalho, são algumas das recompensas almejadas. $\mathrm{O}$ conhecimento para além uma bagagem, mas também, um portal de acesso.

A universidade é o campo de formação social, profissional e muitas vezes pessoal. Partindo dessa concepção podemos concluir que a universidade, como o enunciado da palavra já explicito, constitui o conjunto formador do cidadão, ou seja, a universidade abrange ocupa o topo do conhecimento. (suj 222 cur 01 sex 01).

As evocações seguem uma ordem crescente não só de importância mas também de construção. 
Porque a universidade nos leva a uma busca real do conhecimento que irá nos ajudar a realizar com mais competência a nossa razão e mente crítica. E tanto a capacitação e desenvolvimento profissional quanto racional dependerá do conhecimento que adquirimos na universidade. suj 083 cur 01 sex 01

Nas palavras do sujeito acima, sua justificativa na Associação Livre de Palavras, ressaltou que a palavra mais forte em relação à palavra indutora universidade era o conhecimento. Vê-se que ele faz uma elaboração processual de aquisição do conhecimento, e espera que a universidade seja o campo fértil e concretizador da sua formação profissional.

Observamos que a necessidade na vida do ser humano de ter uma formação superior é fundamental, pois se não for assim, a pessoa fica enclausurada em seu conhecimento simples e insuficiente, tendo que se conformar com sua situação, o seu modo de vida, a sua maneira de pensar e o pior, crescendo, sendo bombardeado com ideias e pensamentos distorcidos que o levam cada vez mais para o fundo do poço, para a escuridão do desconhecimento. (suj 083 cur 01).

No seu conjunto, os discentes apresentaram redações pautadas neste contexto de elaboração cooperativa: 1) acesso ao processo de formação acadêmica, através do ingresso na faculdade; 2) aluno assistido pelo professor, trilha o caminho da aprendizagem, da educação e da formação profissional; 3) alcançar o esperado conhecimento, que trará para ele a realização pessoal.

Ao procurarmos pelas Representações Sociais de universidade no grupo de alunos pesquisados, observamos que havia um pano de fundo, uma trama de representações que não estavam na superfície. Elas estavam localizadas por trás das palavras, das frases de efeito, no entorno dos discursos circulantes, naquilo que chama-se de discurso circulante. Confirmávamos o que disse Bardin (1995, p. 14):

Mensagens obscuras que exigem uma interpretação, mensagens com um duplo sentido cuja significação profunda (a que importa aqui) só pode surgir depois de uma observação cuidadosa ou de uma intuição carismática. Por detrás do discurso aparente, geralmente simbólico e polissêmico, esconde-se um sentido que convém desvendar.

O alunos selecionados como bolsistas do ProUni têm no seu ingresso o sentido da reparação, como função de resgate dos níveis do Ensino Fundamental e Médio. Delineia-se aqui, neste trabalho, uma perspectiva semelhante à Educação de Jovens e Adultos - EJA, quando esta surgiu. Vejamos este sentido nas falas a seguir:

O mundo espera e exige que a universidade prepare esses profissionais, pois o tempo não espera por ninguém. E só vive quem se prepara para viver. (suj 221 cur 03 sex 02).

A universidade para mim sempre foi um sonho que hoje vejo uma realidade. $\mathrm{O}$ fato de ter parado de estudar há muito tempo, me deixou sem coragem, achando que não sabia mais de nada e por isso não ia mais enfrentar uma sala de aula no meio de tantos alunos inteligentes, me senti desanimada por ser apenas uma pessoa com nível médio, acordei e estou recuperando o tempo perdido, vi que sou capaz de aprender, de melhorar, uma pessoa que não estuda se perde no tempo e no espaço, era assim que estava. A universidade trás novos horizontes, novas oportunidades de trabalho, o mercado está aí para quem se qualifica, quem 
estuda, por isso estou aqui em busca de um espaço, em busca de conhecimentos, que só a universidade, um curso superior pode me proporcionar. (suj 271 cur 03 sex 02 ).

Estes exemplos ilustram o pressuposto básico moscoviciano, de que as representações sociais são um amálgama de representações coletivas e individuais. Também corroboram as posições de Abric quanto à função prescritiva do Núcleo Central pois as representações são já prescritas antes mesmo de pensarmos à respeito de algo. Normalmente, quando se passa a ter contato/conhecimento sobre algo, a representação já está fixada. As interações humanas são precedidas por representações. Elas são guias dessas interações. É como uma teia que é tecida na ação/pensamento de cada um no compartilhar de duas ou mais pessoas. Cada qual traz o seu fio que é juntado ao fio do outro e, que juntos tecem uma mesma teia. Assim, pode-se afirmar que, para tanto, os fios precisam ser compatíveis. Então, as representações são: [...] como um conteúdo mental estruturado - isto é, cognitivo, avaliativo, afetivo e simbólico - sobre um fenômeno social relevante, que toma forma de imagens ou metáforas, e que é conscientemente compartilhado com outros membros do grupo social. (WAGNER, 1998, p.4)

A propósito das argumentações aqui postas, é igualmente ilustrativo (e reforçado) o modelo que os gráficos assumiram, segundo o EVOC. Nos sujeitos observados verificou-se a concentração de todos os elementos em apenas dois quadrantes, indicando uma coesão muito forte em torno dos sentidos circulantes: alguns pertencem ao Núcleo Central e têm função prescritiva; os demais estão no seu entorno. Esta configuração, entendemos, caracteriza um universo representacional muito bem sedimentado ao longo de séculos. Neste universo predominam os elementos sócio-culturais mais antigos: as crenças, os valores, os símbolos. Ou seja, predominam as interpretações dos fatos, que a eles se sobrepõem.

Finalmente, consideramos que a riqueza do tema e a novidade que o ProUni representa, demanda novas análises do material já coletado, assim também novas coletas, seja no presente - com outras populações; seja no futuro - para confronto com as atuais representações, captadas que foram na sua mais primária emergência.

Sugerimos um estudo longitudinal, para acompanhar a transformação das representações ora captadas tendo em vista que não é possível atingir este objetivo agora, por metodologia transversal, porque sendo o programa recém lançado, no segundo semestre de 2005, ainda não há dados que permitam uma comparação.

Fazemos também sugestões para investimentos nas condições de permanência do aluno no curso superior. Que sejam oferecidos auxílio para transporte, alimentação e material didático. Ainda, comodato de equipamentos (computador, instrumentos de estudo conforme o curso). Sem estes investimentos o governo pode estar criando uma situação perversa: a de despertar no aluno o desejo e satisfação por estar incluído no ensino superior, já que dispõe da bolsa integral ou parcial, mas sem condições de arcar com as despesas inerentes ao processo de formação acadêmica, tais como transporte, material didático, alimentação e outros. Há alunos que vêm para as aulas diariamente, das cidades da grande Natal e até mais distantes. Grande parte utiliza o transporte disponibilizado pelos municípios de origem, já que não dispõem de recursos financeiros para prover tal despesa. Quando acontece algum motivo para o carro não vir para Natal, este aluno fica impossibilitado de comparecer às aulas. "Muitas vezes a bolsa que conseguem na particular é parcial, e ainda assim não têm condições de mantê-la, por questões de dificuldades financeiras. (suj 093 cur 02 sex 02). 
Assim, faz-se necessário estruturar uma rede de apoio aos estudantes que se deslocam de suas cidades de origem para as cidades polos de oferta das bolsas do ProUni. As sugestões são diversas. Dentre elas, a de se criar um pool com as prefeituras e preparar alojamentos que acomodem os estudantes durante a semana ou todo o período letivo. Assim, além da segurança, estariam sendo criadas as condições necessárias para se evitar a evasão e o retorno sem o êxito esperado.

\section{REFERÊNCIAS BIBLIOGRÁFICAS}

1. ABRIC, Jean-Claude. A abordagem estrutural das representações sociais. In: MOREIRA, A.S.P.; OLIVEIRA, D.C. de. (Orgs.) Estudos interdisciplinares de representação social. Goiânia: $A B$, 1998. p. $27-38$

2. BARDIN, Laurence. Análise de conteúdo. Lisboa: Edições 70, 1995.

3. CARVALHO, M. R.; ROAZZI, A.; ANDRADE, E. R. G. As classificações múltiplas na pesquisa de Representações Sociais e o levantamento do campo semântico como pré-requisito ao PCM. Apresentação na II Jornada Internacional sobre representações Sociais. Florianópolis: Hotel Maria do Mar, 19 a 22 de setembro de 2001.

4. MOREIRA, Antônia S.P. (Org). Perspectivas Teórico-Metodológicas em Representações Sociais. João Pessoa: UFPB, 2005.

5. MOSCOVICl, Serge. A representação social da psicanálise. Rio de Janeiro: Zahar Editores, 1978.

6. __ Idéias e seu desenvolvimento - Um diálogo entre Serge Moscovici e Ivana Marková. In: __ Representações sociais: investigações em psicologia social. Petrópolis, RJ: Vozes, 2003. p. $305-387$

7. _ Introdução: o poder das idéias. In: em psicologia social. Petrópolis, RJ: Vozes, 2003. p.07-28

8. _ O O fenômeno das representações sociais. In: Representações sociais: investigações em psicologia social. Petrópolis, RJ: Vozes, 2003. p.29-109

9. NÓBREGA, Sheva Maia da. Sobre a Teoria das Representações Sociais. In: MOREIRA, Antonia Silva Paredes. (Org.) Representações Sociais. Teoria e Prática. João Pessoa: Ed. Universitária /Autor Associado, 2001, p. $55-87$

10. OLIVEIRA, Fátima .O. de; e WERBA Graziela C. Representações sociais. In: JACQUES, M.C. Psicologia social contemporânea. Petrópolis,RJ: Vozes, 1998. p. 104 - 117

11. REINERT, M. Alceste. Une méthodologie danalyse des données textuelles et une application: A. G. Nerval Bulletin de Methodologie Sociologyque, 28, 24-54. 1990.

12. ROAZZI, Antonio. Categorização, formação de conceitos e processos de construção de mundo: Procedimento de classificações múltiplas para o estudo de sistemas conceituais e sua forma de análise através de métodos de análise multidimensionais. Cadernos de Psicologia, v. 1, p. 1-27, 1995.

13. ROSA, Annamaria Silvana de. A "Rede Associativa": uma técnica para captar a estrutura, os conteúdos, e os índices de polaridade, neutralidade e estereotipia dos campos semânticos relacionados com as Representações Sociais. In: MOREIRA, Antônia Silva Paredes (Org). Perspectivas Teórico-Metodológicas em Representações Sociais. João Pessoa: UFPB, 2005. p. 61-128.

14. SÁ, Celso Pereira de. Núcleo Central das Representações Sociais. Petrópolis, RJ: Vozes, 1996. 
15. VERGÈS, Pierre. Lévocation de largent : une méthode pour la définition du noyau central dune représentation. Bulletin de psychologie. Paris, T.45, n. 405, p. 4-7, 1992.

16. WAGNER, Wolfgang. Representações sociais: Gênese, estrutura e relações. In: MOREIRA, A.S.P.; OLIVEIRA, D.C. de. (Orgs.) Estudos interdisciplinares de representação social. Goiânia: $A B, 1998$. p. $03-25$

17. _. Descrição, explicação e método na pesquisa das representações sociais. In: JOVCHELOVITCH, Sandra (Org.). Textos em Representações Sociais. Petrópolis: Editora Vozes, 1998. 